\title{
Journal of Intellectual Capital: a review of emerging themes and future trends
}

\author{
Marco Bellucci - University of Florence, IT \\ Giacomo Marzi - University of Lincoln, UK (ORCID: 0000-0002-8769-2462) \\ Beatrice Orlando - University of Ferrara, IT \\ Francesco Ciampi - University of Florence, IT \\ Published on Journal of Intellectual Capital
}

\section{FULL TEXT (DOI): https://dx.doi.org/10.1108/JIC-10-2019-0239}

\section{Structured Abstract}

Purpose: This article aims to provide a bibliometric and systematic literature analysis of studies published in the Journal of Intellectual Capital (JIC) from 2014 to 2018 in order to highlight emerging themes and future trends.

Methodology: The analysis focused on 187 papers published in the JIC over five years. A scientometric approach to data mining enabled the detection of patterns in the dataset. Precisely, the investigation was conducted by integrating a bibliometric analysis on VOSviewer with a systematic literature review.

Findings: Four main streams of research have emerged in the JIC during the years of the analysis: reporting and disclosure of intellectual capital; intellectual capital research in universities, education and public sector; knowledge management; intellectual capital, financial performance, and market value.

Research implications: The study offers compelling insights into the topics covered by the Journal of Intellectual Capital by identifying the main research gaps and trends along with future research avenues.

Originality: Prior scholars mostly focused on systematic literature reviews, while the use of bibliometric methods generally seems to be a missing tile in the research domain. Also, none of the extant studies have focused on the Journal of Intellectual Capital regarding the 2014 to 2018 period. The use of both bibliometric and systematic approaches to literature review delivered remarkably fine-tuned results in terms of factors such as citations, contents, and evolution of clusters over time.

Keywords:

Intellectual capital, systematic literature review, bibliometric analysis, bibliographic coupling, VOSviewer, intellectual capital reporting, knowledge management.

Article classification:

Research paper

\section{Introduction}

This study aims to review the articles appeared on the Journal of Intellectual Capital in the last five years, as a mean to draw a pattern of past and future avenues of development of this well-recognized outlet. Considering the importance of the Journal in the research panorama and for intellectual capital (IC) research in particular, our hope is that the outcome of our study will be useful for both IC 
scholars, who seek to find and explore gaps in the research domain, and for those practitioners, who wish to improve their knowledge of the topic.

Since the intellectual capital concept was introduced by Galbraith (1969), scholars emphasized its centrality for firm's survival and growth, performance, competitiveness and innovativeness (Porter 1985, Kogut and Zander 1996, Davemport 1999). Despite the abundance of attention on the topic over time, the notion and the influence of IC still remain either oblique or elusive (Bontis 1998, Swart 2006; Mariano and Walter, 2015). As a matter of fact, IC proved itself to be a very versatile, dynamic and contemporary concept, capable to raise an increasing scholar interest year by year and to renew itself. This fashion was well-reflected by publications appearing in the JIC in the studied time range. IC is the critical capacity of managing knowledge-based intellect through detangling the meaning of symbols (Reich 1991), while it is strongly tied to the idea of the learning organization (Argyris 1992, Bontis 1998). This construct refers to that combination of knowledge and experiences which leverage firm wealth (Andriessen 2004). Thereby, IC springs from the process of knowledge creation of firms thriving to compete based on continuous improvement (Senge 1990).

IC is an intangible component, a form of tacit knowledge, which contributes the most in the process of firms wealth creation (Nelson and Winter 1982, Youndt, Subramaniam and Snell 2004) and that can be further specified into five sub-dimensions: the human capital, the structural capital, the organizational capital, the process capital, and the customer, relational or social capital (Wiig 1997, van Dijk et al., 2016). The large success and the importance of the topic are also sustained by the wealth of the existing literature reviews (Petty and Guthrie 2000, Serenko and Bontis 2004; Serenko et al., 2010; Pedro, Leitão and Alves 2018; Vătămănescu et al., 2016).

The Journal of Intellectual Capital (JIC) is the cornerstone of IC studies, the leading publications outlet that reflects the notable recent evolution of the research field (Serenko and Bontis 2004; Serenko et al., 2010). To date there is no literature review exclusively dedicated to the Journal of Intellectual Capital for the period from 2014 onwards. Furthermore, in the past few months, JIC encountered a series of changes in the editorial board, with a new Editor-in-Chief, new members and a renovated mission for the journal. This resounding gap motivated current bibliometric and systematic literature analysis of publications appeared on JIC (Heck and Bremser, 1986; Sullivan, 1999; Zinkhan and Leigh, 1999) from 2014 to 2018.

The methodology was explicitly designed to provide answers to hot questions such as: how publications in the Journal of Intellectual Capital evolved considering a change in the management of the Journal? What are the relevant themes and future trends in the field of IC as they emerge by publications in the journal? What are the main streams of research currently existing and how they are they characterized?

To achieve aforementioned goals, we integrated two different methods of analysis, bibliometric and systematic review methods. The sample includes the entire population of the 187 papers published on JIC from 2014 to 2018. In addition, the interpretation of results was fine-tuned thanks to the interview with the new Editor-in-Chief, Professor Merrill Warkentin.

The results show that JIC publications mostly gravitates around four different streams of research, grouped by theme and consistency. The evolution of the clusters let emerge the shift of the attention of researchers and a change in the relevance of different topics over-time, thus providing extremely valuable insights on future research frontiers and pathways of the Journal.

For the remainder, the paper is organized as follows. Section 2 explains the research method. The interview with the editor in chief of the Journal of Intellectual Capital, Professor Merrill Warkentin, is reported in section 3. Section 4 is dedicated to a comprehensive analysis of the Journal's articles for the period 2014 to 2018 . Section 5 provides our conclusions.

\section{Methods}

\subsection{Methodological notes about the interview process}

For the longest time scholars in social sciences have used the practice of interviewing experts as a mean for exploring a phenomenon and gaining precious insights. Moreover, as any entrepreneurial 
or managerial activity, leading a journal intrinsically implies that the experience and personality, along with the culture and the background of the editor, influence the development of the journal. Precisely, information on the past experiences and background of the Editor in Chief may represent a valuable help to better understand his thoughts and ideas about the past and future of the journal. (Day, 2007; Marzi et al., 2017, 2018; Serenko and Bontis, 2017).

At methodological level, the interview protocol is based on a semi-structured questionnaire. Questions to the Editor in Chief are open-ended and are aimed to elicit the personal footprint, changes in journal's board, and upcoming challenges of IC as a field of study.

First, an initial set of questions have been prepared and compared to other interviews with editors in academic fields (Fisher and van Zwet, 2015; Nahai and Bernard, 2015; Schmidt-Radde, 2016). Then, the protocol was reviewed by an external independent reviewer. The interview with the Editor in Chief of the Journal of Intellectual Capital, Professor Merrill Warkentin, took place in June 2019, via Skype. It lasted one hour in total. The conversation was recorded and, subsequently, tabulated for analysis purposes. The plot of the interview was anticipated via e-mail.

\subsection{Methodological notes about bibliometric and systematic literature analysis}

The first step of the analysis was the collection of papers published on JIC for the period between 2014 and 2018. Papers were collected from the Scopus database. An additional double check performed using WOS Core Collection and EBSCO databases allowed us to verify that all the papers published in the JIC between 2014 and 2018 were already included in our Scopus dataset.

The data collection was performed on March 4th, 2018. The research query was "ISSN (1469-1930)" where "ISSN" is the International Standard Serial Number of the journal. This query permitted us to capture all the papers published on JIC by retrieving them via the ISSN of the journal (Marzi et al., 2018).

The collection was restricted to "Article" and "Review" published in English, thus excluding output editorials, notes, and corrections. Our final dataset included 187 peer-reviewed papers published between 2014 and 2018, representing all the papers published on JIC from 2014 to 2018.

Data were analyzed by using the software VOSviewer 1.6.8. We used bibliographic coupling as the aggregation mechanism for the papers and co-wording analysis for keywords. (Caputo et al., 2019). Bibliographic coupling occurs when two studies both cite a third study as shown in Figure 1.

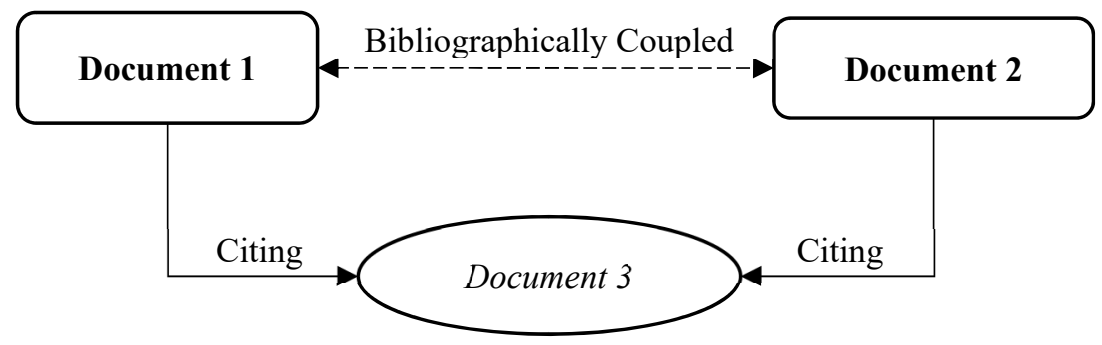

Figure 1 - Representation of Bibliographic Coupling

This allows us to answer the following questions: "How does the intellectual structure of the research stream reflect the richness of the theoretical approaches? How has the intellectual structure of small niche X developed through time?" (Zupic and Čater, 2015).

Differently, co-word analysis allowed us to investigate the frequency of specific terms occurring together in the keyword lists of the papers analyzed in the present study. The output of the co-word analysis is a map representing the network of interrelations between intellectual and cognitive structures of a field of study or a journal (Zupic and Čater, 2015). In our case, the co-word analysis is aimed to let emerge such a network for JIC.

The VOS analysis graphically shows the affinity of terms. Affinity depends on the distance between the items. Thus, the smaller the distance is between the terms, the stronger the interrelation is between them (van Eck and Waltman, 2014). The software also clusters papers by grouping them based on 
similarities. Each cluster represents a stream of research or a topic. Finally, the size of the dots represents the normalized citation value of a unit of analysis. The size of a dot shows its relative importance in the plot and the field under study (van Eck and Waltman, 2014). The result of the VOS analysis is presented in Figure 3, 4, and 5. Figure 3 shows the results of the co-word analysis, whilst Figure 4 and 5 depict the outcome of bibliographic coupling.

Based on the result of the VOS and following the methodological suggestion by Smart et al. (Smart et al., 2003) we then performed a systematic literature review on the most relevant papers in our sample.

Consistently with indications gathered from prior studies (Cepeda-Carrion, Cegarra-Navarro, and Cillo 2019, Natalicchio, Petruzzelli, and Garavelli 2014, Natalicchio, Ardito, Savino, and Albino 2017), the systematic literature review was aimed to provide a complete, exhaustive summary of results relevant to our study.

The literature review showed the main topics, the findings, and best managerial practices emerging from the analysis of each thematic cluster. The selection of the papers from each of the four clusters was based on the normalized citation count and a critical examination of the content of each paper. These selection criteria are in line with the best literature reviews practices used to analyze the intellectual structure of specific journals (Caputo et al., 2018; Marzi et al., 2018). As the result and in line with the approaches adopted by similar papers on similar fields of study (Caputo et al., 2018), fifteen relevant papers for each cluster were selected and analyzed. Finally, based on the findings emerged from the literature review, combined with the insights received by the interview with the editor, a set of future research avenues grouped by the cluster is proposed.

\section{Journal of Intellectual Capital: an interview with the editor}

The authors interviewed the new Editor in chief of the Journal of Intellectual Capital, Professor Merrill Warkentin, in two different occasions: before and after the bibliometric exploration. The interview addresses questions relating to the profile, objectives, essential topics, characteristics, and the future of the Journal.

Can you please describe yourself as a scholar?

As a scholar, my main research focus is on Information Systems and Decision Making. I am the James J. Rouse Endowed Professor of Information Systems in the College of Business at Mississippi State University. [...]. I like pursuing research questions that interests me. I get involved in a lot of projects. I currently have over thirty projects underway as well as eighteen papers under review.

I came to Mississippi state nineteen years ago and it has been fantastic. I'd say it is a great place for being a scholar. I made the traditional American career path: assistant professor, associate professor, full professor, chair, etc.

Recently, I was contacted by the publisher of the JIC [...] and I decided to accept their offer because they needed a lot of help. I decided to offer my experience because the Journal needed some fixing. Basically, they work for a new and better Journal.

\section{Can you tell us something about your experience with JIC?}

I tried to broaden the scope and include more topics, such as creativity, knowledge management, etc. in order to increase submission from scholars outside the traditional accounting or even management research domain.

I worked hard to change the entire workflow together with the editorial board, changing the way review process works, trying to speed up the process to offer timely feedback to authors. There were a lot of changes to the administration of the Journal.

I am really trying to change the process of review. The editorial assistant, Veronica Scuotto, has been very helpful. The main thing we wanted to do is to have real associate editors. We never really had them before, there were people who never really handled papers. There are layers between me and 
reviewers. The associate editors, grouped by area of expertise, can invite reviewers, they collect reviews and make their recommendations. I make the final decisions basing on both associate editors' recommendations and reviewers' suggestions. Basically, we want diverse, high-quality papers [...], whether it is a qualitative paper, empirical or even conceptual/theoretical type of paper, but we want to understand how far is created individual IC, how firms leverage IC and how they preserve and protect the intellectual paper.

The Journal was already using manuscript central ScholarOne, but there was not a good quality review system. I completely changed the workflow so that we have a more structured process, so it is easier to have papers tracked. The process is now faster, we have qualified reviewers, the associate editors also make recommendations for me. I think the process has largely improved.

We wanted to revive the board, to have a real editorial board. They really never had it before [...] and then I changed the workflow, that's the biggest part.

What advice can you give to the authors that would like to publish in the JIC? What is the philosophy behind the JIC? What sets it apart from other journals?

IC emerges from the difference between the book value and the market value. [...] So, if a firm has this mismatch that means it has a great future potential. Many companies in the high-tech business have it, companies like Google, Facebook, Amazon, Biotech. [...] But where does it comes from? From the intelligence, $[\ldots]$ the collaboration between people. [...] So, how do firm create knowledge, IC? How they grow it, foster it, leverage it, check it?

Because it is an outstanding Journal with very high international rankings. [...] it has good value and good visibility, and this trend will improve eventually. The audience is very broad, from scholars to business people.

As the new EIC, how do you see the future of the Journal?

This new team is the most valuable asset of the Journal. In the future, we want to further improve the submission process, along with the quality of papers. In the last period, we did a lot more submissions than before. I expect a further increasing number of submissions in future. Special issues play a fundamental role in the sense that they help improve the attractiveness of the Journal and achieve a differentiated positioning.

Which advice would you give to those authors who wish to publish in the JIC?

In the future, more scholars from the knowledge management and accounting fields will study the topic of IC creation and development. My advice for perspective authors is to write solid research papers. Papers must be very well grounded on prior studies. In addition to quality researches and solid theory, I suggest to non-native writers to have the paper effectively edited for language. It is very hard for ideas to shine if the language is not correct. Moreover, every methodology is welcome as long as the paper is of high quality.

\section{Journal of Intellectual Capital: a bibliometric analysis and a review of the relevant literature} This section presents the results of the bibliometric analysis on 187 papers published on JIC from 2014 to 2018, along with the results of the VOS analysis and the systematic literature review. As shown by Figure 2, the average annual increase of $10 \%$ in papers published in the JIC underscores the existence of an increasing attention by scholars toward this outlet. For that, it can be deemed the paramount Journal for IC issues. 


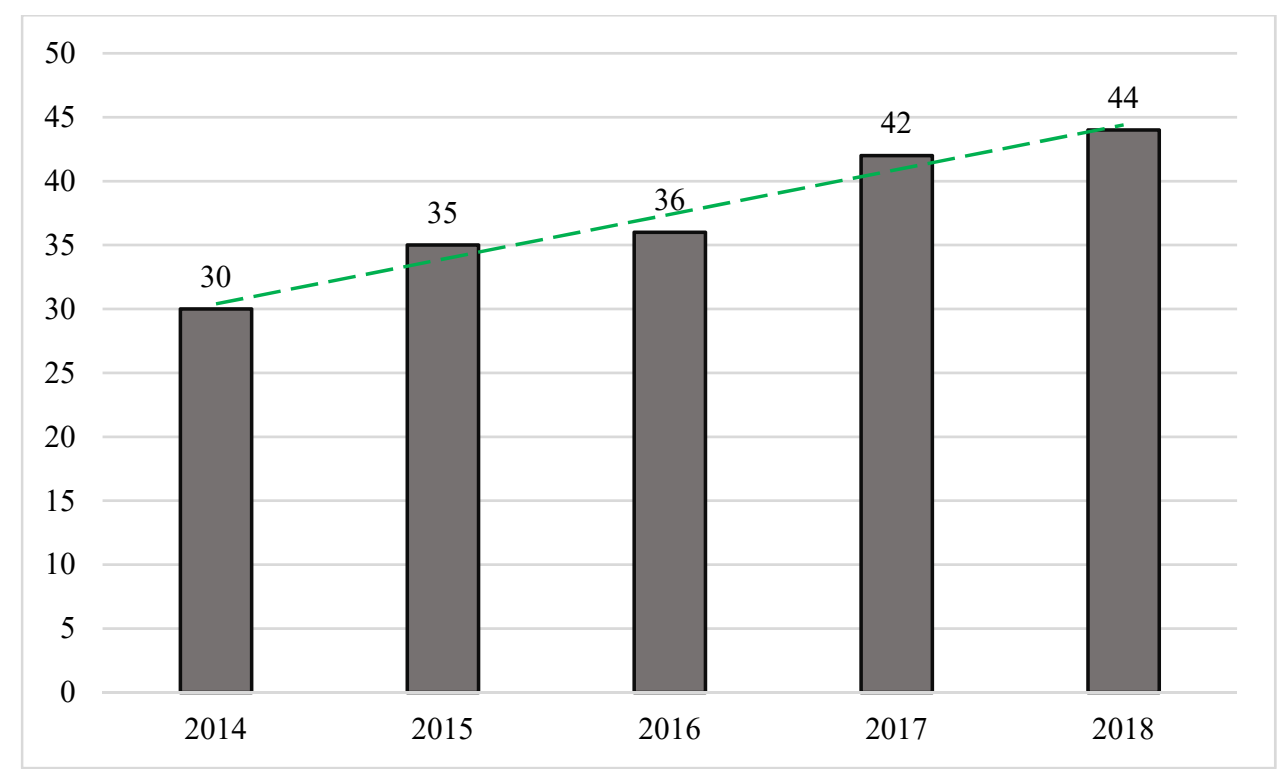

Figure 2 - Papers distribution among the years

Table 1 reports a breakdown by institution. Only institutions with at least 3 papers published in the JIC were considered.

Notably, Macquarie University has the highest number of papers and of citations. It is also possible to note the prominence of Italian scholars among others. As a matter of fact, Italy has six institutions with at least three papers published in the JIC.

\begin{tabular}{|l|l|l|l|}
\hline Institution & Country & $\begin{array}{l}\text { Number of } \\
\text { Papers }\end{array}$ & $\begin{array}{l}\text { Total } \\
\text { Citations }\end{array}$ \\
\hline Macquarie University & Australia & 16 & 263 \\
\hline McMaster University & Canada & 6 & 91 \\
\hline University of Ferrara & Italy & 6 & 57 \\
\hline National Research University Higher School of Economics & Russian Federation & 6 & 51 \\
\hline University of Salento & Italy & 4 & 88 \\
\hline Università Politecnica delle Marche & Italy & 4 & 32 \\
\hline University of Vigo & Spain & 3 & 32 \\
\hline National Chengchi University & Taiwan & 3 & 17 \\
\hline Second University of Naples & Italy & 3 & 18 \\
\hline University of Salerno & Italy & 3 & 11 \\
\hline Lappeenranta University of Technology & Finland & 3 & 59 \\
\hline University of Cassino and Southern Lazio & Italy & 3 & 5 \\
\hline
\end{tabular}

Table 1 - Institutions with at least 3 papers published in the JIC

In connection with Table 1, Table 2 shows the total number of papers published in the JIC broken down by scholars' country. Table 2 also reveals that Italian scholars are the most prolific authors for the JIC, with 68 papers published between 2014 and 2018. Besides, Italy is the most cited country, with 578 papers and an average number of citations per paper of 8.5. Interestingly, even if Australia has less than half of Italy's paper, it has an average number of citations per paper of 16.21 that is similar to Spain (11.58) and United Kingdom (10.92).

\begin{tabular}{|l|l|l|}
\hline Country & $\begin{array}{l}\text { Number of } \\
\text { Papers }\end{array}$ & $\begin{array}{l}\text { Total } \\
\text { Citations }\end{array}$ \\
\hline Italy & 68 & 578 \\
\hline Australia & 32 & 519 \\
\hline Spain & 17 & 197 \\
\hline United Kingdom & 12 & 131 \\
\hline Portugal & 11 & 54 \\
\hline
\end{tabular}




\begin{tabular}{|l|l|l|}
\hline Russian Federation & 11 & 82 \\
\hline Canada & 9 & 107 \\
\hline Finland & 7 & 148 \\
\hline Brazil & 6 & 63 \\
\hline Austria & 5 & 48 \\
\hline France & 5 & 13 \\
\hline Iran & 5 & 16 \\
\hline Malaysia & 5 & 61 \\
\hline New Zealand & 5 & 52 \\
\hline Thailand & 5 & 55 \\
\hline Ireland & 4 & 49 \\
\hline Taiwan & 4 & 23 \\
\hline Denmark & 3 & 27 \\
\hline Germany & 3 & 20 \\
\hline Hong Kong & 3 & 91 \\
\hline India & 3 & 42 \\
\hline United States & 3 & 12 \\
\hline
\end{tabular}

Table 2 - Countries with at least 3 papers published on JIC

Figure 3 provides the visual representation of the co-word analysis. Topics are aggregated by relevance for the JIC during the period 2014 to 2018, based on authors' keywords.

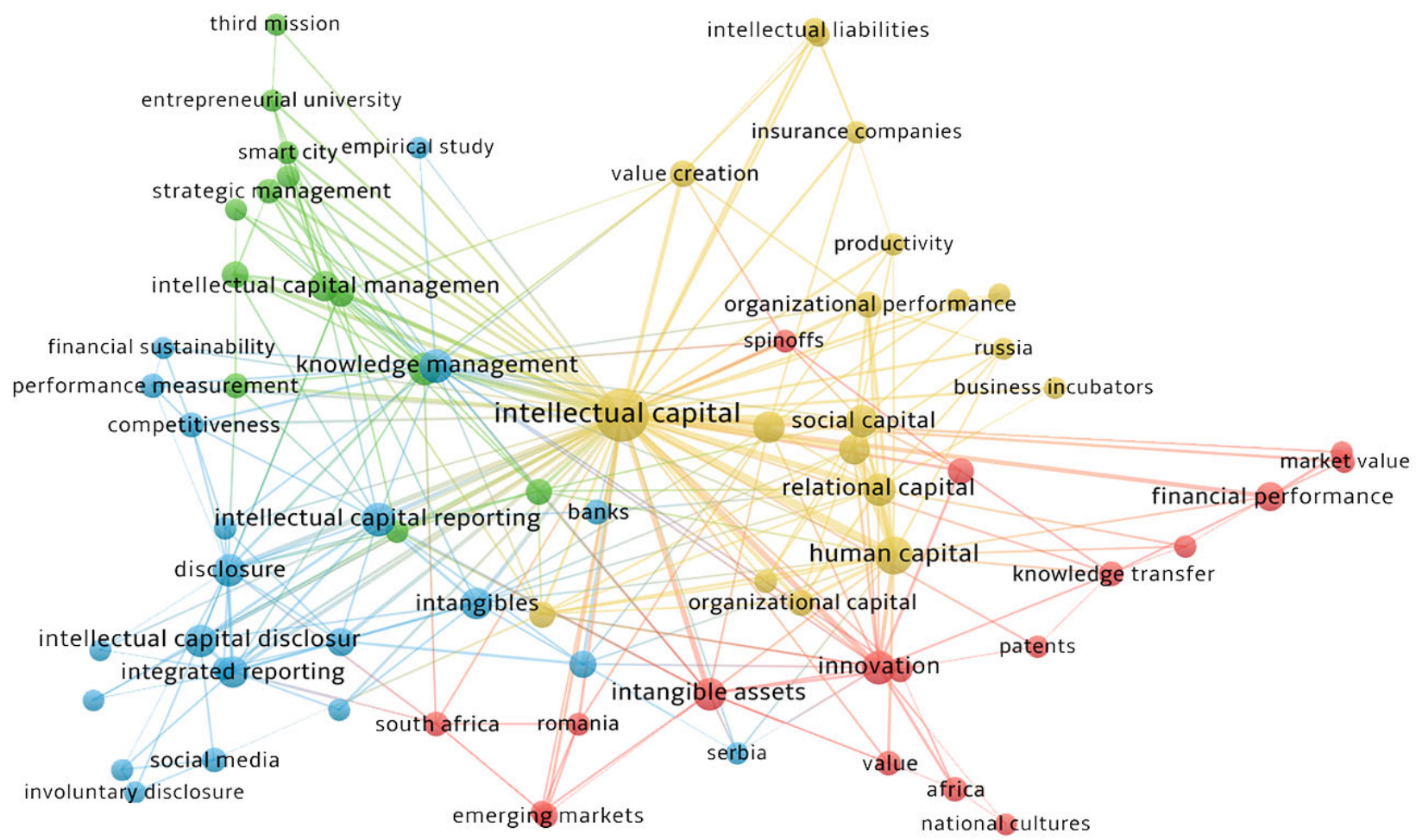

Figure 3 - Result of the co-word analysis

As shown by Figure 3 and Table 3, four thematic clusters of keywords emerge from the analysis. These clusters mostly reflect the results of the bibliographic coupling analysis. However, it is possible to note that the keyword "intellectual" represents a bridge between the clusters in a similar way to the keywords "knowledge management", "innovation", and "intellectual capital reporting". 


\begin{tabular}{|c|c|c|c|c|c|c|c|}
\hline \multicolumn{2}{|l|}{ Blue Cluster } & \multicolumn{2}{|l|}{ Yellow Cluster } & \multicolumn{2}{|l|}{ Red Cluster } & \multicolumn{2}{|l|}{ Green Cluster } \\
\hline Keyword & OC & Keyword & OC & Keyword & OC & Keyword & $\mathbf{O C}$ \\
\hline $\begin{array}{l}\text { intellectual capital } \\
\text { reporting }\end{array}$ & 13 & intellectual capital & 124 & innovation & 13 & Universities & 11 \\
\hline $\begin{array}{l}\text { knowledge } \\
\text { management }\end{array}$ & 13 & human capital & 25 & intangible assets & 12 & $\begin{array}{l}\text { intellectual capital } \\
\text { management }\end{array}$ & 8 \\
\hline $\begin{array}{l}\text { intellectual capital } \\
\text { disclosure }\end{array}$ & 12 & relational capital & 12 & $\begin{array}{l}\text { financial } \\
\text { performance }\end{array}$ & 7 & public sector & 5 \\
\hline disclosure & 11 & social capital & 11 & entrepreneurship & 4 & Italy & 4 \\
\hline integrated reporting & 10 & Performance & 10 & Africa & 3 & Stakeholders & 4 \\
\hline intangibles & 9 & structural capital & 8 & $\begin{array}{l}\text { emerging } \\
\text { markets }\end{array}$ & 3 & higher education & 3 \\
\hline accounting & 6 & value creation & 5 & $\begin{array}{l}\text { intellectual } \\
\text { property }\end{array}$ & 3 & strategic management & 3 \\
\hline strategy & 5 & organizational capital & 4 & $\begin{array}{l}\text { knowledge } \\
\text { transfer }\end{array}$ & 3 & & \\
\hline banks & 3 & $\begin{array}{l}\text { organizational } \\
\text { performance }\end{array}$ & 4 & South Africa & 3 & & \\
\hline competitiveness & 3 & $\begin{array}{l}\text { small to medium } \\
\text { sized enterprises }\end{array}$ & 4 & value & 3 & & \\
\hline $\begin{array}{l}\text { performance } \\
\text { measurement }\end{array}$ & 3 & intellectual liabilities & 3 & & & & \\
\hline social media & 3 & & & & & & \\
\hline
\end{tabular}

Table 3 - Main keywords with at least three occurrences (OC) divided by cluster

The co-word analysis based on authors' keywords digs to light the main relevant topics. Differently, the bibliographic coupling analysis identifies the existing streams of research. Precisely, our bibliographic coupling analysis (Figure 4) identified four well-polarized clusters of papers representing likewise streams of research. Based on above results, we distinguished the following four major themes of research:

- Reporting and disclosure of intellectual capital (blue cluster)

- Intellectual capital research in universities, education and public sector (green cluster)

- Knowledge management and intellectual capital (red cluster)

- Intellectual capital, financial performance, and market value (yellow cluster) 


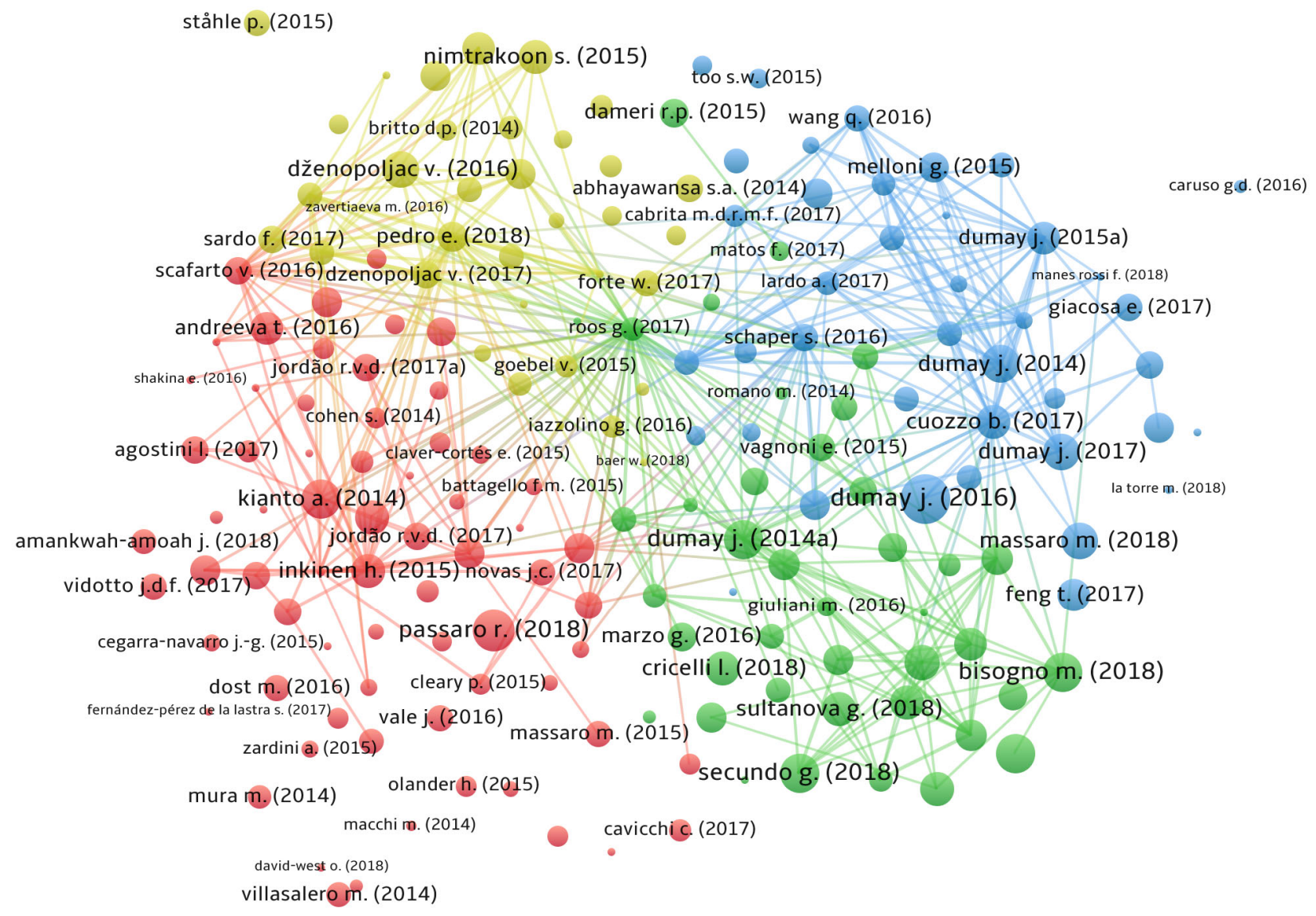

Figure 4 - Result of the bibliographic coupling analysis

Figure 5 explains the time distribution for each cluster. Thus, it provides insights on the evolution over time for each stream of research.

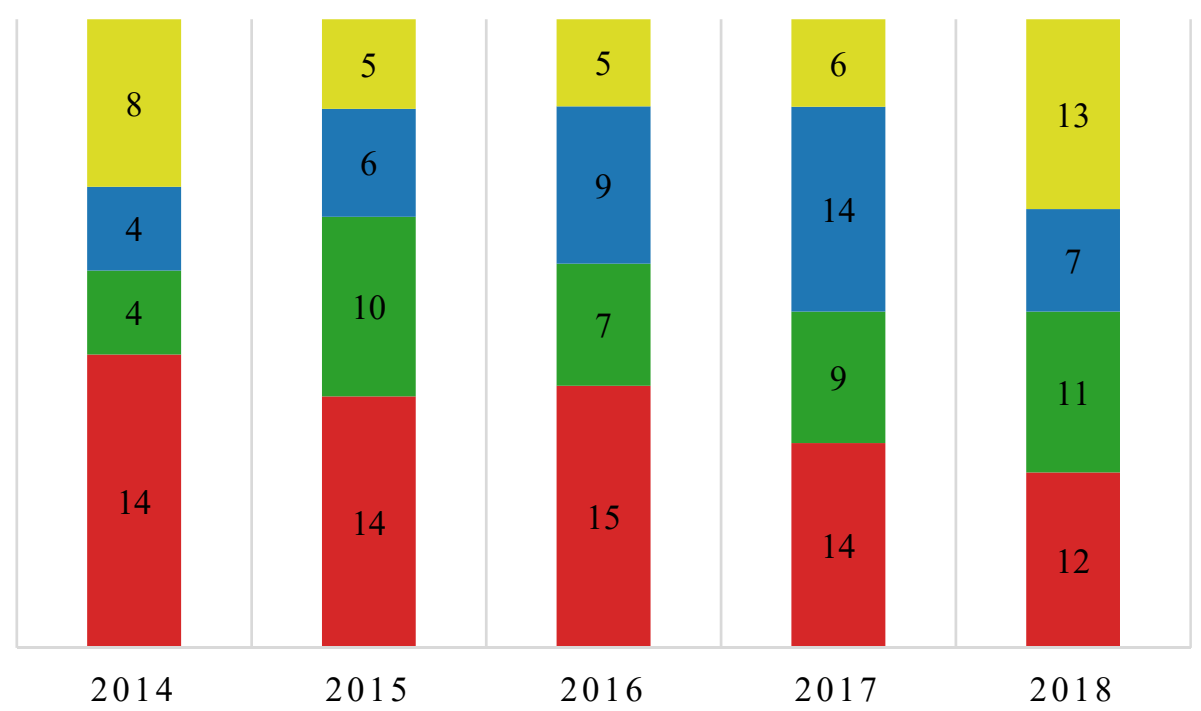

Figure 5 - Time distribution per cluster (bibliographic coupling analysis)

In terms of numbers of papers, the consistency of the red cluster (the one related to knowledge management) has decreased during the last two years. By contrast, the yellow one (related to the link between IC, financial performance, and market value) increased. The pattern for the other two cluster appears more nuanced. 
Anyway, the trend of all clusters can be deemed almost constant. This may indicate that the identified streams of research kept their relevance for scholars throughout the five-year period under analysis.

\subsection{Reporting and disclosure of intellectual capital (blue cluster)}

This bibliographic cluster includes forty articles that mainly focus on the integrated reporting and disclosure of IC. Although IC is essential to understand how firms create value, its disclosure often falls short due to the lack of established IC frameworks for reporting or a scarce commitment by companies and other organizations. Bini, Dainelli and Giunta (2016) run a content analysis on the disclosures of business models presented in the strategic report of a sample of listed UK firms that are active in high-tech sectors and find that few companies use business model disclosure to underline the contribution of their IC to value capture and creation. What emerges is that business model descriptions inadequately illustrate the connections among the business model components and how IC is functional to a company's value creation process. Farooq and Nielsen (2014) found evidence that analysts are more likely to follow companies that disclose more about IC and demonstrate that the most significant IC disclosures for analysts are those related to human capital and business strategy. This article inspects the effect of IC disclosure on analysts through a sample of biotechnology companies listed on the Copenhagen Stock Exchange between 2001 and 2010.

The main contribution by Melloni (2015) is to offer evidence of the quality of the IC disclosure provided in the Integrated Reporting (IR) framework. A manual content analysis of all the reports available in the International IR Council (IIRC) database was used in combination with a test of the relationship between the positive IC disclosure tone and specific characteristics that may lead managers to manipulate their disclosure. The author found out that a positive tone of IC disclosure is associated with deteriorating performance, larger size and higher level of intangibles. These results supported the idea that IC disclosure is often used as an impression management tool. De Silva, Stratford and Clark (2014) also highlighted a certain orientation to avoid negative information. They used content analysis to observe IC reporting configurations of New Zealand companies over a longitudinal period and compared knowledge-intensive firms with traditional product-based firms. They found that a vast amount of IC reporting is presented in a discursive form and without reporting on negative aspects or news.

Dumay and Guthrie (2017) overcome traditional studies of annual reports and evaluate if involuntary disclosure, defined as what external stakeholders and "stake seekers" disclose about an organization, is relevant for stakeholders. The outcome of their conceptual study is the proposal of a shift in the research agenda concerning IC disclosure and the discussion of several possible new research questions on this topic. Feng, Cummings and Tweedie (2017) emphasized the need for further studies being capable of carefully interpreting the potential impact of IR on the activities and the daily practice of companies, either through general reporting or specific disclosure of IC. Their analysis adopted in-depth, semi-structured interviews with key IR stakeholders in Australia, including two IR pilot organizations, one professional association, an accounting professional body, an accounting firm and two IIRC officials. They argued that, though the concept of "integrated thinking" is central to IR, a better clarification of what integrated thinking means in practice for companies and other organizations could improve the understanding and exploitation of the IC disclosure potential of IR. Dumay (2016) also focused on integrated reports and provides a personal review of the future implications in terms of IC reporting in light of the resurging attention on intangibles caused by the current momentum of sustainability reporting and IR.

Schaper, Nielsen and Roslender (2017) built on the findings of semi-structured interviews with representatives of sixteen companies and discussed the implications of a shift of point of view, from IC reporting informed by an accounting perspective to IC-centric disclosures. The authors found a tendency towards integrated forms of IC reporting into corporate social responsibility reports or annual reports and conclude that this trend is often motivated by the necessity to avoid reporting overload. 
Many contributions within this cluster try to shed light on the quality of IC reporting. Wang, Sharma and Davey (2016) run a content analysis on annual reports to determine the quality and scope of voluntary IC disclosure by IT firms operating in China and India and found that Indian IT firms tend to perform better than Chinese IT firms. External capital is the most frequently disclosed category both in China and India; the least disclosed categories are human capital, in India, and internal capital, in China. In a similar way but in a very different context, Low, Samkin and Li (2015) used content analysis to study the characteristic of voluntary IC disclosure by universities in Australia, New Zealand, and the UK. They found that human and internal capital are the most disclosed categories and very frequently IC disclosures tend to be narrative.

The analysis of the literature comprised in the blue cluster brings out several ideas for further research. These include, but are not limited to, opportunities for additional research aimed at investigating:

- the IC reporting behavior amid diverse varieties of firms (i.e. knowledge intensive or traditional product-based companies, different sectors, various geographical regions, etc.) (De Silva et al., 2014);

- the adoption of communication channels for IC disclosures enabling a more direct interaction with internal and external stakeholders (Schaper et al., 2017);

- the inclusion in reporting systems of detailed accounts of supportive conditions for, and results of, learning, human capital formation and empowerment;

- how research methods different than content analysis (e.g. interviews or surveys) could help generate additional insights for advancing the analysis of IC reporting;

- new frameworks and guidelines for assisting organizations in voluntary disclosing of IC information (Low et al., 2015);

- the motivations and theoretical frameworks that can lead firms to voluntary disclose on IC;

- the adoption of IC disclosure as an impression management tool, also focusing on the visual and graphical aspects of reports;

- the conceptualization of how IR and integrated thinking are interrelated, and the effects in terms of IC disclosure of this connection;

- how the different conceptions of IR and integrated thinking affect organizational behavior (Feng et al., 2017);

- the declination of reporting at the micro-level of collaborating persons, groups and projects, rather than being macro-level only and institutionally focused;

- the reliability of involuntary IC disclosures that originate from outside a company and which are the methods for authentication (Dumay and Guthrie, 2017);

- how IC reporting frameworks change across sectors and countries and the potential opportunities to develop a unitary approach;

- the evaluation of the intermingling of research and practice, in terms of if and how research findings inspired and influenced the most recent trends in corporate reporting on IC;

- the links between IC disclosure, dialogic accounting and stakeholder engagement;

- the IC disclosure in third sector organizations and public institutions.

The topic of IC reporting in public administrations led us to the next cluster labelled: "Intellectual capital research in universities, education and public sector" (green cluster).

\subsection{Intellectual capital research in universities, education and public sector (green cluster)}

This bibliographic cluster includes forty-one articles that are mainly focused on IC research in the public sector with particular consideration of universities and the education field. Although the public sector is not one of the most addressed objects of analysis for IC research, their critical role played in our knowledge-based society makes universities an intriguing region of exploration. The primary objective of Sangiorgi and Siboni (2017) was to examine the extent and characteristics of voluntary IC disclosure in Italian higher-education organizations and to estimate the opinion of university administrators on IC and its disclosure. Findings are based on a content analysis of voluntary social 
reports issued by Italian universities and a survey which was submitted to all top managers of Italian universities. The study found a noteworthy volume of IC disclosure in sustainability reports. Moreover, administrators prove to be conscious of the positive implication, in terms of responsiveness to stakeholders calls and effectiveness of policy making of correct IC management and reporting. Veltri and Silvestri (2015) also focused on IC disclosure from universities. They adopted a case study approach to investigate the report of a South African university (UFS) and to verify if it matches the main recommendation of the International IR Council Framework in terms of integrating IC and nonIC disclosures in a single document. However, their analysis showed that the interconnections among stakeholders are not discussed, the information is not always integrated, the data do not present an outlook perspective, and the organizational mechanisms to create and share value are not detailed.

Bisogno, Dumay, Manes Rossi and Tartaglia Polcini (2018) used a structured literature review to investigate forty-seven articles on the current state and future perspectives of IC literature in education. They argued that IC research in the education sector is still very limited and mostly focused on IC in European contexts using a case study approach. Therefore, new studies approaching diverse educational, methodological and geographical scenarios should be developed. In other words, IC research in education could be more effective in contributing to policy making discussion if it expanded its frontiers. Secundo, Dumay, Schiuma and Passiante (2016) adopted the collective intelligence approach and tried to deliver a new dashboard for IC management in universities. Their underlying assumption is that higher-education institutions are actors of a collective intelligence system where the tangible and intangible assets are coordinated towards the attainment of strategic objectives. The study of this coordination ultimately made possible the understanding of how IC helps creating a positive social and economic impact on the region where the university is operating, along with positive externalities for the society at large.

Martin-Sardesay and Guthrie (2018) drew on case studies of the Australian public sector universities in order to contribute to the IC literature in education by discussing the connection between performance measurement systems and academic human capital. The empirical evidence discussed by the authors can support policy makers and public administrations in avoiding unintentional effects of performance evaluations systems on human capital. Vagnoni and Oppi (2015) also focused on managerial aspects. They contribute to the advancement of techniques for practitioners managing university hospitals and discuss the role of IC for university hospital strategic management after developing and applying an IC framework to augment the visualization of strategic IC components. The purpose of Secundo, Elena-Perez, Martinaitis and Leitner (2015) is to configure a "IC Maturity Model" that could be a part of the strategic management of universities and could enable a better IC measurement and management. Their model proposes a staged framework to stimulate a change within a university based upon its current level of IC management maturity. Ramirez and Gordillo (2014) aimed to configure a framework for identification and assessment of IC in Spanish highereducation institutions. They used empirical evidence to recognize which are the IC components to be measured. They defined a set of indicators which could aim universities to present more useful data to their stakeholders, contributing to greater transparency, accountability, and comparability in the higher education sector.

Roos (2017) combined a literature review with data from an Australian project on state-based economic intricacy to provide new insights for the streams of literature relating to structural holes, economic complexity theory, non-price-based competition, and knowledge management. The discussion on the generation of national prosperity is summarized through an IC perspective.

Analyzing and connecting the literature belonging to the blue cluster points out several ideas for further research. These include, but are not limited to, opportunities for additional research delving into:

- the debate around the creation and management of IC in academia (De Silva et al., 2014);

- the disclosure of universities IC on social media, websites and other web platforms (Low et al., 2015); 
- the diverse behavior of small or large, private or public, centralized or decentralized universities in terms of the extent of IC reporting and communication (Low et al., 2015);

- the empirical adaptation of the IC Maturity Model to a vast array of different higher education institutions (Secundo et al., 2015);

- the identification, development and prioritization of standardized IC indicators that could be implemented across various universities in the same countries or across countries;

- the potential connections of IC management with universities' strategic objectives;

- how universities manage academic human capital to counterbalance the unintended consequences of performance measurement systems (Martin-Sardesai and Guthrie, 2018);

- the strengths and weaknesses of the guidelines and frameworks that can be used for knowledge management and reporting (Abhayawansa, 2014);

- how to consider gender-related issues in IC measurement, reporting and management in universities;

- The relevance of resilience to social and environmental shocks for IC management in the education system of contemporary societies.

The topic of knowledge reporting leads us to the next cluster titled: "Knowledge management and intellectual capital" (red cluster).

\subsection{Knowledge management and intellectual capital (red cluster)}

This bibliographic cluster includes sixty-nine articles focused on the management of knowledge. Contributions on IC and knowledge management (KM) are systematically linked and are both useful to address the issue of knowledge in organizations. Against this background, the aim of Kianto, Ritala, Spender and Vanhala (2014) was to discuss a theoretical model on how intellectual assets and their management practices interrelate in generating organizational performance. Hussinki, Ritala, Vanhala and Kianto (2017) also aimed at observing the impact of different patterns of IC and KM practices on organizational performance. On the one hand, they provided further evidence that organizations featuring high levels of IC and KM practices are likely to outperform less knowledgefocused firms; on the other hand, they demonstrated that organizations with high levels of IC but only low utilization of $\mathrm{KM}$ can still reach the innovation scores of organizations featuring high levels of IC and KM.

Other works analyze the mediating effect of intangible capital on the relation between KM and IC. Ramadan, Dahiyat, Bontis and Al-dalahmeh (2017) used a survey dataset collected from employees of IT companies operating in Jordan to conclude that knowledge documentation, transfer, acquisition and creation have the strongest effect on IC. Khalique, Bontis Bin Shaari and Isa (2015) also shared the interest in research on KM in extra-European organizations operating in technological sectors and provided a framework for entrepreneurs, managers and policy makers oriented to the management of IC within the Pakistani context. In particular, the aim of their article is to assess the connections between IC components and organizational performance in SMEs operating in the electronics manufacturing sector.

Jordao and Novas (2017) also provided a conceptual model capable of explaining how the processes of generating, acquiring, managing, and sharing knowledge in SMEs networks can be influenced by the organizational background and the network development process. Furthermore, Molodchik, Shakina and Barajas (2014) explored the implications of six elements of IC - management quality, human resources capabilities, innovation, internal process capabilities, networking capabilities, and customer loyalty - in terms of decision-making processes for KM. Other work focuses on how intellectual assets linked to structural and human capital are leveraged. In particular, Campanella, Peruta and Del Giudice (2014) investigated, through a regression analysis, the main factors influencing the progression of KM practices. They contributed to the literature on financial, organizational and cognitive performances of European science parks. Calza, Dezi, Schiavone and Simoni (2014) resorted to a literature-based analysis providing a theoretical tool that can be used to 
study IC in business incubators. Their contribution builds on the literature about the intangible assets of new generation business incubators by examining how these organizations use IC to pursue their mission.

It is increasingly important for organizations to understand how knowledge is created, managed, measured and evaluated. There are few earlier studies analytically combining IC and KM perspectives and demonstrating how IC assets and their management devices might interact in value creation. This notwithstanding, organizational performance, is increasingly grounded on knowledge-related issues. In one of the first studies reviewing the empirical literature on IC and performances, Inkinen (2015) pointed out that IC influences firm performance mainly through relations, combinations and intermediations, and that there is a strong relationship between IC and firm's innovation capacities.

Analyzing the literature comprised in the red cluster suggests several new promising research avenues that could be explored. These include, but are not limited to, opportunities for additional research that study:

- how the processes of generating and managing knowledge are linked with SMEs network creation process (Jordão and Novas, 2017);

- the interconnections between IC and KM that can lead to organizational benefits, innovation and the improvement of market performances (Hussinki et al., 2017);

- the diverse meaning that IC management can assume in particular local contexts, such as economically advanced countries or developing countries, democratic countries rather than oligarchic or even dictatorial regimes, liberal market economies or coordinated market economies, etc.;

- the determinants of the scarcity of knowledge workers in less developed countries and the relative implications for SMEs (Khalique et al., 2015);

- the repercussions of science parks and incubators outside of Europe in terms of IC, human capital, social capital, creativity and impacts on the regions where they operate (Campanella et al., 2014);

- the conceptual and theoretical implications arising from the interconnections between IC assets and KM practices, and their measurement (Kianto et al., 2014);

- the features of the links between static and dynamic elements in knowledge-based organizations (Kianto et al., 2014);

- who is best positioned to manage, measure and report on IC within a company;

- both theoretical and applied approaches that could lead to a better understanding of which are the most pivotal sectors for the regional and national development in terms of organizational IC (Pedro et al., 2018);

- how intangible resources take part in value creation in the era of knowledge-based economy, and the definition and measurement of the components that can be integrated into a company's strategy (Dzenopoljac et al., 2017);

- the specific connections between IC, human capital, creativity, performances and the attitude of companies towards innovation in developing countries;

- the formation of human capital through individual decisions, actions and motivations rather than through structured organizational initiatives;

The link between IC, innovation and firm performances leads us to the next cluster titled: "Intellectual capital, financial performance and market value" (yellow cluster).

\subsection{Intellectual capital, financial performance, and market value (yellow cluster)}

This bibliographic cluster comprises thirty-seven articles that primarily shed light on the interconnections between IC, financial performances and market value. As discussed in the previous sections, several national and supranational institutions have produced guidelines, models and frameworks for reporting that provide a clear understanding of firm value creation and firm performances. The purpose of Abhayawansa (2014) was to study these guidelines in light of a focus 
on the external disclosure and explanation of IC. The systematic literature review on empirical studies on IC published in the period from 1960 to 2016 provided by Pedro, Leitao and Alves (2018) show that of the 777 papers included in the review, 189 deal with the relationship between IC and performance.

Kim and Taylor (2014) analyzed a sample of 160 Australian listed firms and provide new evidence on the productivity of the components of IC after IFRS adoption. Their results show that the productivity of human capital, structural capital and IC are positively related to share price. Anifowose, Abdul Rashid, Annuar and Ibrahim (2018) applied resource-based theory and find a significant positive relationship between IC efficiency and corporate book value of companies listed on Nigeria Stock Exchange. Vishnu and Gupta (2014) shared the extra-European viewpoint and investigate the positive link between IC and financial performances of pharmaceutical firms in India. Morariu (2014) used Value Added Intellectual Coefficient (VAIC) model to empirically investigate the interconnection between IC and corporate performances in an emergent economy. In particular, he studied the relative impact of various aspects of IC on the performances of Romanian companies. Nimtrakoon (2015) also built on the VAIC model by adding an extra component, namely, relational capital efficiency. He explored and compared the extent of IC among technology firms listed on five ASEAN stock exchanges, and examines the link between firms' IC, financial performance, and market value. Sardo and Serrasqueiro (2017) also investigated these specific links, using a sample of listed firms operating in fourteen countries in Western Europe for the period between 2004 and 2015, with particular reference to the connection between ownership concentrations and IC. Their results confirm that IC is pivotal for firms' value creation and that human capital is a key factor for companies' wealth. Dženopoljac, Janoševic, and Bontis (2016) also used the VAIC model to understand if and how IC creates value in the Serbian information communication technology sector. Authors used ROE, ROA, ROIC, profitability, and asset turnover as measures of financial performance: their findings suggest that capital-employed efficiency has a strong effect on financial performances. Dzenopoljac, Yaacoub, Elkanj, and Bontis (2017) provide insights into the relationship between IC and corporate performance among Arab companies and challenge the validity of the VAIC model as a measure of IC's contribution to performance. Research hypotheses were tested through multiple regression models and the sample included 100 publicly traded Arab firms ranked as top performers in terms of assets, sales, and market value.

Analyzing and connecting the literature belonging to the blue cluster points out several promising research avenues that could be investigated. These include, but are not limited to, opportunities for additional research exploring:

- what links between IC and business models are currently disclosed by companies and which is their utility in terms of business drivers (Bini et al., 2016);

- the impacts of artificial intelligence, machine learning, blockchain, cloud integration and other new technologies on IC and firm performances;

- the relationships between IC reporting, the degree of BM communication and the reactions of the financial market (Bini et al., 2016);

- a cross-country comparison about market capitalization and quality of IC disclosure;

- if strong firm performance is associated with better IC, which in turn supports firm performance, using a recursive model (Inkinen, 2015);

- the value relevance of IC by assessing the association between IC and corporate book value of listed and non-listed companies in developing countries, with particular reference to Africa, Asia and East-Europe (Anifowose et al., 2018);

- the intermingling of IC, financial performance, and market value using longitudinal analyses (Sardo and Serrasqueiro, 2017);

- which are the effects of IC reporting in terms of productivity and efficiency;

- other aspects of financial and non-financial performance, like, liquidity, productivity, environmental sustainability, creativity, asset efficiency, etc.; 
- the role of IC as a driver of economic growth and the implication for policymakers in terms of GDP formation and growth (Ståhle et al., 2015);

- potential metrics that could assist the assessment of the financial and non-financial impacts on firms of their investments in IC (Kim and Taylor, 2014).

\section{Conclusions}

Our study shed light on the past and future trends of JIC by clustering papers over a period of five years. In brief, our results show that the success and importance of JIC was increasing thus far, per the effect of two main factors: the centrality of IC theme in business and management studies and the change in the editorial board of the Journal. Our study has significant implications either for scholars or practitioners. First, it allowed to define the main research streams, their trend, and their consistency. Future scholars may use this result to position their papers, detect research gaps and hot topics. Second, practitioners may rely on this representation to have a summary picture of the topic and to discover what is new and relevant for the future of firms in terms of management and reporting. By discussing the state of the art and the future research trends of publications in the Journal of Intellectual Capital, our study also largely contributes to the existing body of knowledge on IC. The Journal of Intellectual Capital is one of the most relevant outlets for this area of research. Thus, by explicitly and originally focusing our bibliometric and systematic literature analysis on this journal, we not only provide a one-of-a-kind literature review dedicated to the JIC, but we also reconcile and advance the specific research domain. We believe one of the implications of the present contribution is to offer food for thought to researchers interested in making "meaningful contributions that are either theoretical, methodological, or empirical in nature" (Patty and Guthrie, 2000, p. 170) to the IC research domain.

The investigation allowed us to sense the DNA and the emerging spirit of the Journal - after the appointment of the new Editor in Chief - compared to former management, to discover patterns in publications over a period of five years, and to capture future and most relevant research directions. On one hand, the study is useful for those scholars who wish to contribute and submit their papers to JIC; on the other hand, our findings have a broader audience than the readers of JIC, because they impact the entire research domain and have relevance for all IC scholars.

Furthermore, our integrated approach to methodology offers highly precise results. In fact, previously, scholars have mostly adopted the systematic literature review method. Qualitative literature analysis can suffer from biasedness of the researcher and poor rigor (Tranfield, Denyer and Smart 2003). We have therefore integrated the systematic analysis with the use of a bibliometric method. Bibliometric analyses are deemed extremely valuable because of their capacity to map the structure and development of scientific fields (Zupic and Čater 2015).

From the joint bibliometric and systematic literature analysis of 187 papers published on JIC for the period between 2014 and 2018, it emerged the existence of four main research streams: reporting and disclosure of IC; IC research in universities, education and public sector; knowledge management; IC, financial performance, and market value. Our findings brought up the relevance and consistency of either single topics or streams of research. Notably, we detected that, over time, IC has gained importance for financial studies. Previously, IC was prevalently studied in the accounting domain. We argue that this result can be explained by the current dominance of the knowledge and digital economy, since firms' value is increasingly tied to intangible assets. The centrality of this aspect for scholars also mirrors the increased value of IC assets in financial markets. As for that, practitioners should pay attention to new ways to create and manage a firm's IC. Consistently, the number of studies on the relationship between knowledge and IC has remained almost stable over time. Moreover, we argue that micro-foundations of IC will acquire growing importance eventually. Aspects, such as creativity, entrepreneurial orientation, or, more in general, personal traits, value and belief of human resources can largely explain the firm's capability to create the IC of the firm. Future scholars should pay attention to factors bridging the three firm's levels: the micro, meso and organizational levels. 
Furthermore, the potential helpfulness of mixed-methods has long been recognized in the business, management and accounting literature (Bryman and Bell, 2015; Birnberg et al., 1990) as a way of corroborating research findings and enriching an understanding of results in light of a wider contextual analysis (Petty and Guthrie, 2000). Although content analyses, case studies, surveys, and experiments have all been performed in IC research, few studies have attempted a multi-method approach to data collection and analysis. We believe the integration of different methods could enrich many of the research strands on IC highlighted in the previous sections.

This study also provides practitioners with the capacity to sense the future direction of the field. In the previous section we provide some suggestions for further research in each of the four research streams reviewed in section 4 . The following Table 4 summarizes, for each cluster, these research suggestions and declines these ideas on the perspective of practitioners interested in exploring, from different perspective, the future trends of IC management and reporting.

\begin{tabular}{|c|c|}
\hline \multicolumn{2}{|c|}{ Topics and potential future directions for IC research } \\
\hline $\begin{array}{l}\text { Reporting and disclosure of intellectual capital } \\
\text { - } \text { new frameworks and guidelines for voluntary } \\
\text { disclosure of IC information; } \\
\text { the most pressing motivations that lead firms to } \\
\text { voluntary disclose on IC; } \\
\text { - } \text { adoption of IC disclosure as an impression } \\
\text { management tool; } \\
\text { - } \text { visual and graphical aspects of IC reports; } \\
\text { - conceptualization of how IR, integrated thinking } \\
\text { and IC are interrelated; } \\
\text { reliability of involuntary IC disclosures that } \\
\text { originate from outside a company; } \\
\text { how IC reporting frameworks change across } \\
\text { - } \text { sectors and countries; } \\
\text { links between IC disclosure, dialogic accounting } \\
\text { and stakeholder engagement; } \\
\text { IC disclosure in third sector organizations and } \\
\text { public institutions; } \\
\text { IC reporting behaviors amid diverse varieties of } \\
\text { firms; } \\
\text { the effects of academic research findings on the } \\
\text { recent trends in corporate reporting on IC; } \\
\text { communication channels for IC disclosures } \\
\text { enabling a more direct interaction with internal } \\
\text { and external stakeholders; } \\
\text { how interviews or surveys could support the } \\
\text { analysis of IC reporting. }\end{array}$ & $\begin{array}{l}\text { Intellectual capital research in universities, education } \\
\text { and public sector } \\
\text { - how to manage academic human capital to } \\
\text { counterbalance the unintended consequences of } \\
\text { performance measurement systems; } \\
\text { - } \text { the strengths and weaknesses of the guidelines } \\
\text { and frameworks that can be used for knowledge } \\
\text { management and reporting; } \\
\text { - gender capital and gender-related issues in } \\
\text { universities' reporting; } \\
\text { - creation and management of IC in academia; } \\
\text { disclosure of universities IC on social media, } \\
\text { websites and other web platforms; } \\
\text { different behaviors of universities in terms of IC } \\
\text { reporting; } \\
\text { empirical adaptation of the IC Maturity Model to } \\
\text { a vast array of different higher education } \\
\text { institutions; } \\
\text { identification, development and prioritization of } \\
\text { standardized IC indicators for universities; } \\
\text { connections of IC management with universities' } \\
\text { strategic objectives. }\end{array}$ \\
\hline $\begin{array}{l}\text { Knowledge management and intellectual capital } \\
\text { - } \quad \text { interconnections between IC assets and KM } \\
\text { practices, and their measurement; } \\
\text { - } \text { links between static and dynamic elements in } \\
\text { knowledge-based organizations; } \\
\text { - understanding of the most pivotal sectors for the } \\
\text { regional and national development in terms of } \\
\text { organizational IC; } \\
\text { - } \text { roles of intangible resources in value creation in } \\
\text { the era of knowledge-based economy; } \\
\text { connections between IC, human capital, } \\
\text { creativity, performances and the attitude of } \\
\text { companies towards innovation in developing } \\
\text { countries; } \\
\text { links between knowledge and SMEs network } \\
\text { creation process; }\end{array}$ & $\begin{array}{l}\text { Intellectual capital, financial performance, and market } \\
\text { value } \\
\text { - Associations between IC and corporate book } \\
\text { value of listed and non-listed companies in } \\
\text { Africa, Asia and East-Europe; } \\
\text { the effects of IC reporting on productivity and } \\
\text { efficiency; } \\
\text { impacts of IC on other aspects of financial and } \\
\text { non-financial performance: liquidity, } \\
\text { productivity, environmental sustainability, } \\
\text { creativity, asset efficiency, etc.; } \\
\text { role of IC as a driver of economic growth and the } \\
\text { implication for policymakers in terms of GDP } \\
\text { formation and growth; }\end{array}$ \\
\hline
\end{tabular}


- interconnections between IC, KM, innovation and the improvement of market performances;

- the most suitable positions within a company to manage, measure and report on IC;

- diverse meanings of IC management in particular local contexts, such as economically advanced countries or developing countries, democratic countries rather than oligarchic regimes, liberal market economies or coordinated market economies, etc.;

- determinants of the scarcity of knowledge workers in less developed countries and the implications for SMEs;

- the implications of science parks and incubators outside of Europe in terms of IC.
- potential metrics that could assist the assessment of the financial and non-financial impacts on firms of their investments in IC;

- links between IC and business models;

- impacts of artificial intelligence, machine learning, blockchain, cloud integration and other new technologies on IC and firm performances;

- relationships between IC reporting, the degree of $\mathrm{BM}$ communication and the reactions of the financial market;

- cross-country comparisons about market capitalization and quality of IC disclosure;

- feedback-loops between firm performance and IC.

Table $4-$ Potential topics and trends in IC research

The main limitation of the study is that it examines a relatively small number of years. Therefore, in the future, it will be worthwhile to extend this analysis and compare the research ideas hereby highlighted with the contemporary progress at the frontier of IC research. 


\section{References}

Abhayawansa, S.A. (2014), "A review of guidelines and frameworks on external reporting of intellectual capital", Journal of Intellectual Capital, Vol. 15 No. 1, pp. 100-141.

Andriessen, D. (2004), Making Sense of Intellectual Capital: Designing a Method for the Valuation of Intangibles, Elsevier Butterworth-Heinemann, Oxford.

Anifowose, M., Abdul Rashid, H.M., Annuar, H.A. and Ibrahim, H. (2018), "Intellectual capital efficiency and corporate book value: evidence from Nigerian economy", Journal of Intellectual Capital, Vol. 19 No. 3, pp. 644-668.

Argyris, C. (1992), On Organizational Learning, Blackwell, Cambridge, MA.

Bini, L., Dainelli, F. and Giunta, F. (2016), "Business model disclosure in the Strategic Report: Entangling intellectual capital in value creation process", Journal of Intellectual Capital, Vol. 17 No. 1, pp. 83-102.

Birnberg, J. G., Shields, M. D., \& Young, S. M. (1990). The case for multiple methods in empirical management accounting research (with an illustration from budget setting). Journal of Management Accounting Research, 2(1), 33-66.

Bisogno, M., Dumay, J., Manes Rossi, F. and Tartaglia Polcini, P. (2018), "Identifying future directions for IC research in education: a literature review", Journal of Intellectual Capital, Vol. 19 No. 1, pp. 10-33.

Bryman, A. and Bell, E. (2015), Business research methods, Oxford University Press, USA.

Calza, F., Dezi, L., Schiavone, F. and Simoni, M. (2014), "The intellectual capital of business incubators", Journal of Intellectual Capital, Vol. 15 No. 4, pp. 597-610.

Campanella, F., Peruta, M.R.D. and Del Giudice, M. (2014), "Creating conditions for innovative performance of science parks in Europe. How manage the intellectual capital for converting knowledge into organizational action”, Journal of Intellectual Capital, Vol. 15 No. 4, pp. 576596.

Caputo, A., Marzi, G., Maley, J. and Silic, M. (2019), “Ten years of conflict management research 2007-2017: an update on themes, concepts and relationships", International Journal of Conflict Management, Vol. 30 No. 1, pp. 87-110.

Caputo, A., Marzi, G., Pellegrini, M.M. and Rialti, R. (2018), "Conflict management in family businesses: A bibliometric analysis and systematic literature review", International Journal of Conflict Management, Vol. 29 No. 4, pp. 519-542.

Cepeda-Carrion, G., Cegarra-Navarro, J. G., \& Cillo, V. (2019). "Tips to use partial least squares structural equation modelling (PLS-SEM) in knowledge management." Journal of Knowledge Management, Vol. 23, No 1, pp. 67-89.

Davenport, T. (1999), Human Capital, Jossey-Bass, San Francisco, CA.

Day, W. (2007), Readme First for a User's Guide to Qualitative Methods [Book Review], Qualitative Research Journal, Vol. 7, Available at: https://doi.org/10.3316/QRJ0701067.

de Silva, T.-A., Stratford, M. and Clark, M. (2014), "Intellectual capital reporting: A longitudinal study of New Zealand companies", Journal of Intellectual Capital, Vol. 15 No. 1, pp. 157-172.

Dumay, J. (2016), "A critical reflection on the future of intellectual capital: from reporting to disclosure", Journal of Intellectual Capital, Vol. 17 No. 1, pp. 168-184.

Dumay, J. and Guthrie, J. (2017), "Involuntary disclosure of intellectual capital: is it relevant?", Journal of Intellectual Capital, Vol. 18 No. 1, pp. 29-44.

Dženopoljac, V., Janoševic, S. and Bontis, N. (2016), "Intellectual capital and financial performance in the Serbian ICT industry", Journal of Intellectual Capital, Vol. 17 No. 2, pp. 373-396.

Dzenopoljac, V., Yaacoub, C., Elkanj, N. and Bontis, N. (2017), "Impact of intellectual capital on corporate performance: evidence from the Arab region", Journal of Intellectual Capital, Vol. 18 No. 4, pp. 884-903.

Farooq, O. and Nielsen, C. (2014), "Improving the information environment for analysts: Which intellectual capital disclosures matter the most?", Journal of Intellectual Capital, Vol. 15 No. 1, 
pp. $142-156$.

Feng, T., Cummings, L. and Tweedie, D. (2017), "Exploring integrated thinking in integrated reporting - an exploratory study in Australia", Journal of Intellectual Capital, Vol. 18 No. 2, pp. 330-353.

Fisher, N.I. and van Zwet, W.R. (2015), “An interview with Jae C. Lee”, International Statistical Review, Vol. 83 No. 3, pp. 371-404.

Galbraith, J.K. (1969), The New Industrial State, Penguin, Harmondsworth, UK.

Heck, J.L. and Bremser, W.G. (1986), "Six Decades of The Accounting Review: A Summary of Author and Institutional Contributors", The Accounting Review1, Vol. 61 No. 4, pp. 735-744.

Hussinki, H., Ritala, P., Vanhala, M. and Kianto, A. (2017), "Intellectual capital, knowledge management practices and firm performance", Journal of Intellectual Capital, Vol. 18 No. 4, pp. 904-922.

Inkinen, H. (2015), "Review of empirical research on intellectual capital and firm performance", Journal of Intellectual Capital, Vol. 16 No. 3, pp. 518-565.

Jordão, R.V.D. and Novas, J.C. (2017), "Knowledge management and intellectual capital in networks of small- and medium-sized enterprises", Journal of Intellectual Capital, Vol. 18 No. 3, pp. 667692.

Khalique, M., Bontis, N., bin Shaari, J.A.N. and Isa, A.H.M. (2015), "Intellectual capital in small and medium enterprises in Pakistan", Journal of Intellectual Capital, Vol. 16 No. 1, pp. 224-238.

Kianto, A., Ritala, P., Spender, J.-C. and Vanhala, M. (2014), "The interaction of intellectual capital assets and knowledge management practices in organizational value creation", Journal of Intellectual Capital, Vol. 15 No. 3, pp. 362-375.

Kim, S.H. and Taylor, D. (2014), "Intellectual capital vs the book-value of assets: A value-relevance comparison based on productivity measures", Journal of Intellectual Capital, Vol. 15 No. 1, pp. 65-82.

Low, M., Samkin, G. and Li, Y. (2015), "Voluntary reporting of intellectual capital: Comparing the quality of disclosures from New Zealand, Australian and United Kingdom universities", Journal of Intellectual Capital, Vol. 16 No. 4, pp. 779-808.

Mariano, S. and Walter, C., (2015), The construct of absorptive capacity in knowledge management and intellectual capital research: content and text analyses. Journal of Knowledge Management, vol. 19 , no 2, pp. 372-400.

Martin-Sardesai, A. and Guthrie, J. (2018), "Human capital loss in an academic performance measurement system", Journal of Intellectual Capital, Vol. 19 No. 1, pp. 53-70.

Marzi, G., Caputo, A., Garces, E. and Dabic, M. (2018), "A Three Decade Mixed-Method Bibliometric Investigation of the IEEE Transactions on Engineering Management", IEEE Transactions on Engineering Management, In Press

Marzi, G., Rialti, R., Dabic, M. and Caputo, A. (2017), “A mixed methods bibliometric investigation of the World Review of Entrepreneurship, Management and Sustainable Development: from qualitative to quantitative data", World Review of Entrepreneurship, Management and Sustainable Development. In Press

Melloni, G. (2015), "Intellectual capital disclosure in integrated reporting: an impression management analysis", Journal of Intellectual Capital, Vol. 16 No. 3, pp. 661-680.

Molodchik, M.A., Shakina, E.A. and Barajas, A. (2014), "Metrics for the elements of intellectual capital in an economy driven by knowledge", Journal of Intellectual Capital, Vol. 15 No. 2, pp. 206-226.

Morariu, C.M. (2014), "Intellectual capital performance in the case of Romanian public companies", Journal of Intellectual Capital, Vol. 15 No. 3, pp. 392-410.

Nahai, F. and Bernard, E.S. (2015), "20th Anniversary Interview with ASJ Editor-in-Chief Dr Foad Nahai”, Aesthetic Surgery Journal, Oxford University Press.

Nahapiet, J., and Ghoshal, S. (1998). "Social capital, intellectual capital, and the organizational advantage." Academy of Management Review, Vol. 23, No. 2, pp. 242-266. 
Natalicchio, A., Ardito, L., Savino, T., \& Albino, V. (2017). "Managing knowledge assets for open innovation: a systematic literature review." Journal of Knowledge Management, Vol. 21, No. 6, pp. 1362-1383.

Natalicchio, A., Petruzzelli, A. M., \& Garavelli, A. C. (2014). "A literature review on markets for ideas: Emerging characteristics and unanswered questions.” Technovation, vol. 34, No. 2, pp. 65-76.

Nelson, R.R. and Winter, S.G. (1982), An Evolutionary Theory of Economic Change, Belknap Press, Cambridge, MA. New York, NY.

Nimtrakoon, S. (2015), “The relationship between intellectual capital, firms' market value and financial performance: Empirical evidence from the ASEAN", Journal of Intellectual Capital, Vol. 16 No. 3, pp. 587-618.

Pedro, E., Leitão, J. and Alves, H. (2018), "Intellectual capital and performance: Taxonomy of components and multi-dimensional analysis axes", Journal of Intellectual Capital, Vol. 19 No. 2, pp. 407-452.

Petty, R., and Guthrie, J. (2000). "Intellectual capital literature review: measurement, reporting and management." Journal of Intellectual Capital, Vol. 1, No. 2, pp. 155-176.

Porter, M. E., and A. Millar V. A., "How Information Gives You Competitive Advantage." Harvard Business Review, Vol. 63, No. 4 (July-August 1985), pp. 149-160.

Ramadan, B.M., Dahiyat, S.E., Bontis, N. and Al-dalahmeh, M.A. (2017), "Intellectual capital, knowledge management and social capital within the ICT sector in Jordan", Journal of Intellectual Capital, Vol. 18 No. 2, pp. 437-462.

Ramírez, Y. and Gordillo, S. (2014), "Recognition and measurement of intellectual capital in Spanish universities", Journal of Intellectual Capital, Vol. 15 No. 1, pp. 173-188.

Reich, R.B. (1991), The Work of Nations, Alfred A. Knopf, New York, NY.

Roos, G. (2017), "Knowledge management, intellectual capital, structural holes, economic complexity and national prosperity", Journal of Intellectual Capital, Vol. 18 No. 4, pp. 745770.

Sangiorgi, D. and Siboni, B. (2017), "The disclosure of intellectual capital in Italian universities: What has been done and what should be done", Journal of Intellectual Capital, Vol. 18 No. 2, pp. 354-372.

Sardo, F. and Serrasqueiro, Z. (2017), "A European empirical study of the relationship between firms' intellectual capital, financial performance and market value”, Journal of Intellectual Capital, Vol. 18 No. 4, pp. 771-788.

Schaper, S., Nielsen, C. and Roslender, R. (2017), "Moving from irrelevant intellectual capital (IC) reporting to value-relevant IC disclosures: Key learning points from the Danish experience", Journal of Intellectual Capital, Vol. 18 No. 1, pp. 81-101.

Schmidt-Radde, R. (2016), "Interview with the editor", ChemPlusChem, Wiley Online Library, Vol. 81 No. 1, pp. 3-6.

Secundo, G., Dumay, J., Schiuma, G. and Passiante, G. (2016), "Managing intellectual capital through a collective intelligence approach: An integrated framework for universities", Journal of Intellectual Capital, Vol. 17 No. 2, pp. 298-319.

Secundo, G., Elena-Perez, S., Martinaitis, Ž. and Leitner, K.-H. (2015), “An intellectual capital maturity model (ICMM) to improve strategic management in European universities: A dynamic approach", Journal of Intellectual Capital, Vol. 16 No. 2, pp. 419-442.

Senge, P.M. (1990), The Fifth Discipline: The Art and Practice of the Learning Organisation, Doubleday Currency, New York, NY.

Serenko, A. and Bontis, N., (2017), Global ranking of knowledge management and intellectual capital academic journals: 2017 update. Journal of Knowledge Management, vol. 21, no. 3, pp.675-692.

Serenko, A., and Bontis, N. (2004). "Meta-review of knowledge management and intellectual capital literature: Citation impact and research productivity rankings." Knowledge and Process Management, Vol. 11, No. 3, pp. 185-198. 
Serenko, A., Bontis, N., Booker, L., Sadeddin, K. and Hardie, T., (2010), A scientometric analysis of knowledge management and intellectual capital academic literature (1994-2008). Journal of knowledge management, vol. 14, no 1, pp. 3-23.

Smart, P., Tranfield, D. and Denyer, D. (2003), "Towards a methodology for developing evidenceinformed management knowledge by means of systematic review", British Journal of Management, Vol. 14 No. 3, pp. 207-222.

Ståhle, P., Ståhle, S. and Lin, C.Y.Y. (2015), "Intangibles and national economic wealth - a new perspective on how they are linked", Journal of Intellectual Capital, Vol. 16 No. 1, pp. 20-57.

Sullivan, P.H., (1999), Profiting from intellectual capital. Journal of Knowledge Management, vol. 3, no 2, pp. 132-143.

Swart, J. (2006). "Intellectual capital: disentangling an enigmatic concept." Journal of Intellectual capital, Vol. 7, No. 2, pp. 136-159.

Tranfield, D., Denyer, D., and Smart, P. (2003). "Towards a methodology for developing evidenceinformed management knowledge by means of systematic review." British Journal of Management, Vol. 14, No. 3, pp. 207-222.

Vagnoni, E. and Oppi, C. (2015), "Investigating factors of intellectual capital to enhance achievement of strategic goals in a university hospital setting", Journal of Intellectual Capital, Vol. 16 No. 2, pp. 331-363.

van Dijk, A., Hendriks, P. and Romo-Leroux, I., (2016), Knowledge sharing and social capital in globally distributed execution. Journal of Knowledge Management, vol. 20, no 2, pp. 327343.

van Eck, N.J. and Waltman, L. (2014), "Visualizing Bibliometric Networks", Measuring Scholarly Impact, pp. 285-320.

Vătămănescu, E.M., Andrei, A.G., Dumitriu, D.L. and Leovaridis, C., (2016), Harnessing networkbased intellectual capital in online academic networks. From the organizational policies and practices towards competitiveness. Journal of Knowledge Management, vol. 20, no 3, pp. 594619.

Veltri, S. and Silvestri, A. (2015), "The Free State University integrated reporting: A critical consideration”, Journal of Intellectual Capital, Vol. 16 No. 2, pp. 443-462.

Vishnu, S. and Gupta, V.K. (2014), "Intellectual capital and performance of pharmaceutical firms in India”, Journal of Intellectual Capital, Vol. 15 No. 1, pp. 83-99.

Wang, Q., Sharma, U. and Davey, H. (2016), "Intellectual capital disclosure by Chinese and Indian information technology companies: A comparative analysis", Journal of Intellectual Capital, Vol. 17 No. 3, pp. 507-529.

Wiig, K. M. (1997). "Integrating intellectual capital and knowledge management." Long range planning, Vol. 30, No. 3, pp. 399-405.

Youndt, M. A., Subramaniam, M., and Snell, S. A. (2004). "Intellectual capital profiles: An examination of investments and returns." Journal of Management studies, Vol. 41, No. 2, pp. 335-361.

Zinkhan, G.M. and Leigh, T.W. (1999), "Assessing the quality ranking of the journal of advertising, 1986-1997”, Journal of Advertising, Vol. 28 No. 2, pp. 51-70.

Zupic, I. and Čater, T. (2015), "Bibliometric Methods in Management and Organization", Organizational Research Methods, Vol. 18 No. 3, pp. 429-472. 


\section{Author Biographies:}

Beatrice Orlando completed her Ph.D in Business Management and Corporate Finance at Sapienza University of Rome, where she also finished her Master in Finance. Currently, she is Adjunct Professor of Strategies for Business Growth at Sapienza University of Rome. Her research areas cover topics such as innovation adoption, open innovation, and firm's strategy. She has published numerous articles in leading scholarly journals, such as Production, Planning and control, Technology Analysis and Strategic Management, Corporate Social Responsibility and Environmental Management, Journal of Intellectual Capital, and Technology Forecasting and Social Change.

Marco Bellucci (Ph.D) is Assistant Professor in accounting at the Department of Economics and Management of the University of Florence. His research interests include sustainability reporting, stakeholder engagement, corporate social responsibility, social entrepreneurship, and third sector organizations.

Giacomo Marzi is Lecturer in Strategy and Enterprise at the Lincoln International Business School - University of Lincoln (UK). He received his $\mathrm{PhD}$ in Management in 2018 from the University of Pisa. His research is mainly focused on innovation management, new product development, and entrepreneurship. He has authored and co-authored a number of papers that appeared in conferences, edited books and journals such as Human Resource Management Journal, IEEE TEM, JBR, IJCM, IJITM, Scientometrics, and BPMJ among the others. Giacomo is member of IEEE Transactions on Engineering Management editorial board.

Francesco Ciampi is Full Professor of Management at the Department of Economics and Business of the University of Florence. His research is mainly focused on small and medium-sized enterprises, knowledge management, financial management, big data for business management, organizational ambidexterity. He has authored and co-authored a number of papers that appeared in conferences, edited books and journals such as Small Business Economics, Journal of Business Research, Journal of Small Business Management, Management Decision. He has been teaching under-graduate courses in Management since 1998 and post-graduate courses in Management Consulting since 2004. 